\title{
Pre building renovation measurements and efficient decision-making. Danish case study
}

\author{
Hagar Elarga, Christina Sommer, Rune Korsholm Andersen, Carsten Rode \\ Technical University of Denmark, Lyngby ,Denmark
}

\begin{abstract}
Efficient renovation of residential buildings is a cornerstone to achieve the 2020 to 2015 European energy strategy. However, the gap between the actual and estimated energy savings is a challenge, since it jeopardizes the refurbishment's credibility to both the investors and building end users. In this study, a prerenovation measuring concept was investigated as a solution to reduce the energy savings gap through identifying the building baseline and evaluating the occupant's behavior and its influence on the energy performance. The concept was tested on two Danish social housing apartments in Aalborg city where dynamic measurements of indoor environment and energy use were conducted for two weeks. Linear regression relations between the measured indoor and external temperatures were developed and linked to a dynamic building model developed in TRNSYS to predict the heating profiles for the heating season. Short-term measurements before the renovation and the regressed relation to outdoor conditions reduced the difference between expected and actual energy consumption to $3 \%$. The method did not perform well in the renovated apartments where added insulation and improved air tightness decoupled the indoor and outdoor conditions.
\end{abstract}

\section{Introduction}

In order to design and operate more efficient buildings, many classification schemes have been established to predict energy use of buildings, providing a mean to communicate a building's relative efficiency and carbon emissions. These assessment schemes are quantified using different methods as energy performance certificate (EPC) and calculations tools either steady- state or dynamic simulation models according to standard procedures. Both schemes have shown significant discrepancies to predict energy use which risk not achieving the renovation goals (Khoury et al., 2016; Khoury, 2014; Bruman et al., 2014; De Wilde, 2014; Menezes et al., 2012). For ex., the EPC methodology is not defined by the Energy Performance of Buildings Directive (EPBD) and is in the hand of individual member state according to their national requirements, whilst, calculations and even simulation tools may provide different results even for the same building. This is due to: i) the accuracy of calculations tools that may under/overestimate the actual performance and savings. ii) Failure to benchmark the building status before renovation (Maile et al., 2012). iii) Deviations from building design to construction, operation and maintenance of heating ventilation and air conditioning systems (HVAC) installation throughout building lifecycle: with energy use of $50 \%$ to $275 \%$ of predicted values (Rosenberg et al., 2015). iv) Occupants and their interaction with active-passive building features or HVAC installation that are not properly taken into account (Yun et al., 2011). Diverse studies and research have found that when detailed modelling and benchmarking was done on the buildings in their sample, the performance gap averaged at $16 \%$, significantly lower than headline figures based on regulatory calculations, (www.carbontrust.com, 2011). Through the use of feedback loops it is anticipated that the findings, through implementation of the devised framework, will provide better clarity in predicting energy use at the design stage (Bordass et al., 2014). Another study on an office building in Denmark found that when the calculations carried out with the Danish calculation engine (Be-10) for the EPBD were updated to allow for actual heating set points and weather data, the discrepancy between measured and calculated space heating was reduced from $74 \%$ to $14 \%$ (Petersen and Hviid, 2012). A study that combined calibrated dynamic simulation with post-occupancy evaluation and user engagement on a building that was built in 2001 reported an average monthly overall saving of $20.5 \%$ for heating, cooling, lighting, auxiliary energy, and electric equipment as a result of identifying and implementing zero or low-cost energy saving measures with the aid of simulation (Pisello et al., 2012). However, typically designers apply the compliance modelling only to demonstrate compliance with building regulations.

In this study, we have investigated the accuracy of the dynamic building simulation tool after implementing the collected data of the indoor temperature and electrical energy consumption (from a short-term measuring campaign) as input data instead of using design assumptions. The intention behind the pre-renovation measurements was to collect sufficient data during a limited time span, which could describe the occupant behavior and the building envelope's dynamic thermal characteristics, to obtain higher levels of modelling accuracy. 


\section{Methodology}

The methodology section was divided into three parts, in situ measurements and data collection description, prediction of the indoor temperature and dynamic building energy model. The measuring campaign has carried out at non-renovated and renovated apartments of a social housing site in Aalborg Denmark. Wireless sensors technology WST were implemented to reduce occupant's disturbance as much as possible. In addition, a parametric study was executed to optimize the collected data time step, time span i.e. how long the campaign should last to keep the accepted levels of accuracy within a building model developed on TRNSYS software.

In situ measurements and data collection description The in-situ campaign included measuring of different parameters such as heating and electrical consumption, air temperature, relative humidity, $\mathrm{CO} 2$ concentration and occupancy status. In addition to the external climatic conditions (outdoor temperature, solar radiation and wind). This measuring campaign in the field started with a lab test of the sensors to determine their accuracy and determine the sensibility of $\mathrm{CO} 2$ measurements to temperature variations, (Elarga et al., 2018), (Petersen et al., 2018), Figure 1.

\section{Wireless sensors network}

The monitoring and data collection were executed using powered wireless sensors. This solution was chosen due to its wide benefits such as, portability, flexibility, fast set up, the possibility of time synchronization, limited disruption for occupants and cost saving on installation (Mendes et al., 2015). Two particular measuring systems (IC-METERS and WIRELESS-TAGS) was implemented to monitor the indoor temperature, $\mathrm{CO} 2$ and $\mathrm{RH}$ profiles before and after renovation. Investigation and calibration of the latter systems were investigated in climatic chambers of the Technical University of Denmark. The IC METER (version 4.3) communicates through a GSM based module and has accuracy of the $\mathrm{CO} 2$ measurements of \pm 30 ppm or $\pm 3 \%$.

The WIRELESS TAGS are square tags with dimension $4.0 \times 4.0 \times 0.2 \mathrm{~cm}$, which can be distributed over indoor zones and connected to a data router that is connected to the internet via a LAN cable. These tags are capable of measuring air temperature and $\mathrm{RH}$ with accuracy of \pm 0.4 ${ }^{\circ} \mathrm{C}$ and $\pm 2 \%$ respectively, in addition to being able to track the motion of windows and doors. The heating energy measurements was carried out using an ultrasonic heating meter which was implemented with a wireless MBus function i.e. (it is a hierarchical system, with communication controlled by a master (Central Allocation Logic) and end-equipment meters. Figure 2.The electrical consumption was measured using SMAPPEE's instrument Figure 1 to track the overall energy consumption of electrical appliances. SMAPPEE collects real-time and historical production and consumption data down to the electrical appliance level, resulting in actionable insights into the everyday energy use. The unit is connected to the conventional electrical meter via current clamps and to the WIFI internet router via LAN cable. The user is capable to observe and download the time series electrical consumption for all associated appliances Figure 3. On the other hand SMAPPEE installation procedure on site could not be done by a sole visit, it has to be executed through two phases. The first to connect the instrument to local internet WIFI network and to the electrical meter. The second visit is after 2 to 3 weeks for each apartment and it includes turning off all electrical appliances and start to turn it on, one by one and define it on the account dedicated for each apartment to assure that the instrument has identified all connected appliances.

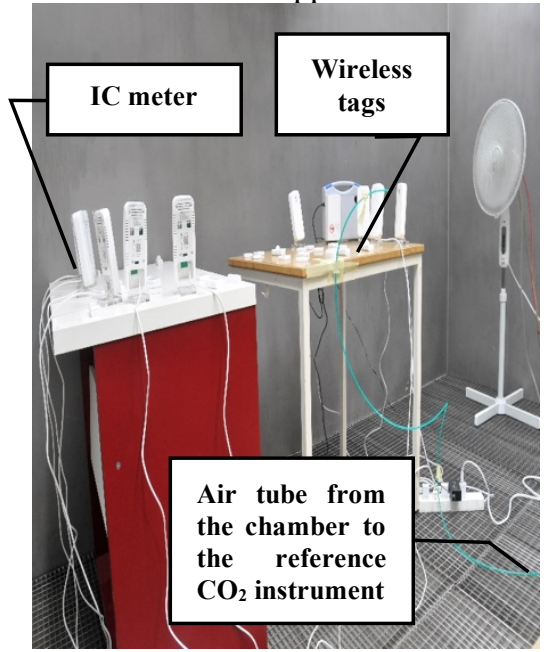

Figure 1: Wireless sensors Lab calibration

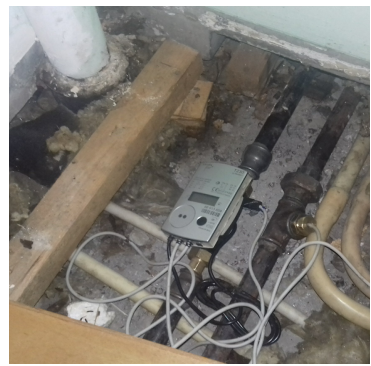

Figure 2: Installed heating meter

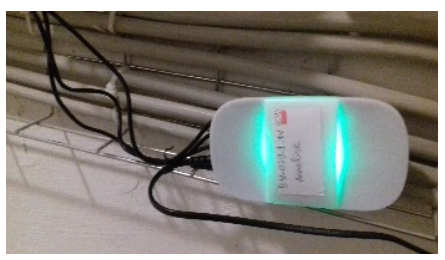

Figure 3: Electrical consumption monitroring meter, SMAPPEE

Testing in the field

A social housing building site in Aalborg, Denmark is currently under renovation, accordingly it was applicable to investigate the performance of non-renovated and renovated apartment's as two case studies.

The first apartment is $90 \mathrm{~m}^{2}$, located in the non-renovated quarter and it is inhabited by a family of 5 persons. The second apartment is $94 \mathrm{~m}^{2}$ and was renovated 2 years prior to the measurements. It is inhabited by a family of 4 persons. Figure 4 shows the In situ installation of the wireless sensors and Figure 5 shows the apartment's 
layouts and the temperature/ $\mathrm{RH}$ wireless sensors locations.

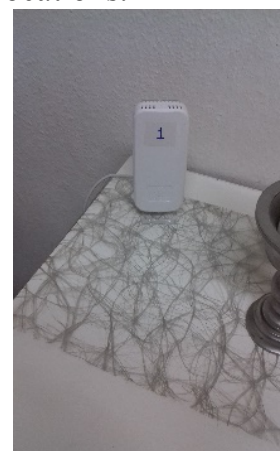

(a)

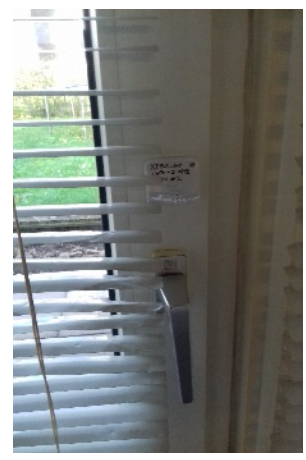

(b)
Figure 4: Wireless sensors Insitu installation a) IC meter, b) Wireless Tag.

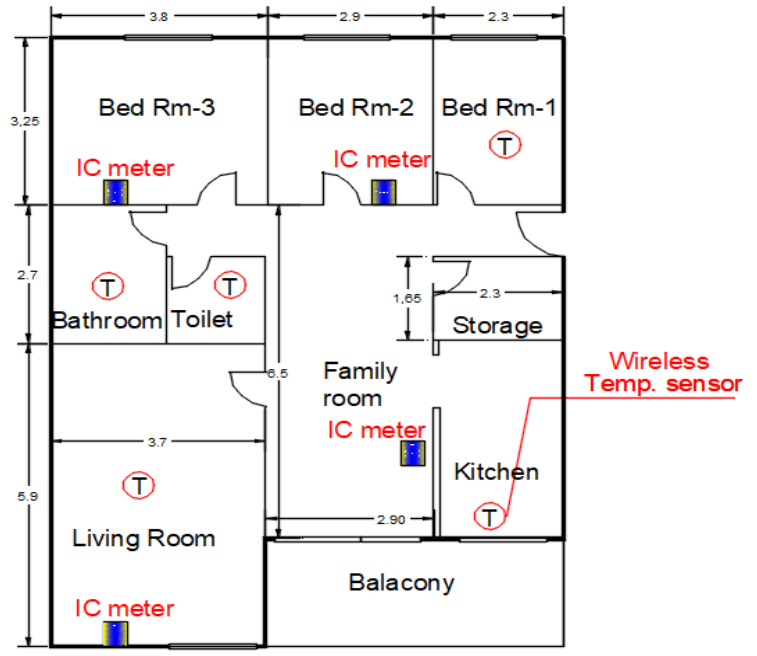

(a)

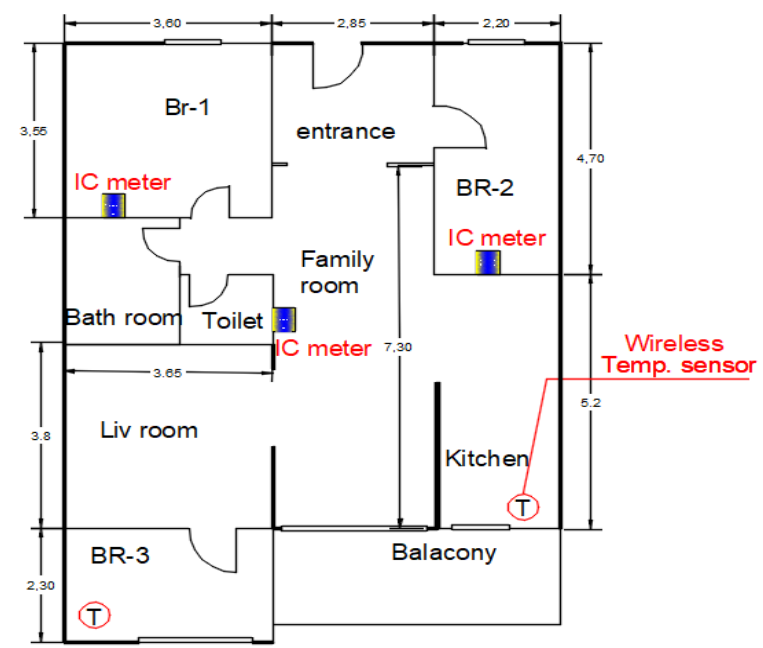

(b)

Figure 5: Apartments under investigation. a) Nonrenovated apartment, b) Renovated apartment.

The wireless temperature sensors (marked with a $\mathrm{T}$ ) measured temperature and relative humidity in 5 minutes intervals. The IC meters measured temperature, relative humidity and $\mathrm{CO} 2$ concentration at 5-minute intervals.

\section{Infiltration rate measurements}

Blower door test illustrated in Figure 6 has been carried out for both the non-renovated and renovated apartments with a differential pressure of $(50 \mathrm{~Pa})$ between the apartment and the staircase. The leakage was measured in both directions (flow direction from the apartment to the outside and vice versa). Test results are shown in Table 1. It is important to highlight that infiltration rate for the nonrenovated was very close to the renovated apartment which raises the problem of construction errors which participates in the gap between expected and actual energy performance after renovation.

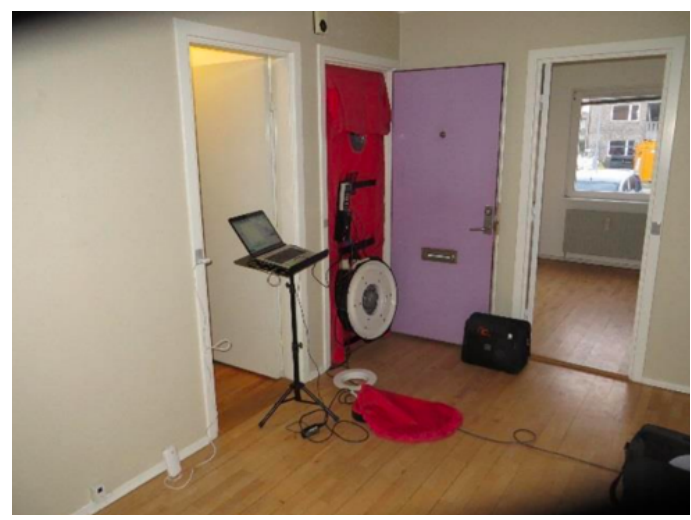

Figure 6: AirBlower door test, non-renovated apartment

Table 1:Infiltration Rates

\begin{tabular}{|c|c|}
\hline Apartment & Infiltration rate $\left(\mathrm{L} / \mathrm{s} . \mathrm{m}^{2}\right)$ \\
\hline Non-renovated & 0.21 \\
\hline Renovated & 0.17 \\
\hline
\end{tabular}

\section{Exhaust ventilation system}

The exhaust ventilation system serves toilet, bathroom is constant air volume which operated $24 \mathrm{~h}$ with $51 / \mathrm{s}$ and $81 /$ s respectively. While the kitchen hood is controlled by the occupant.

\section{Walls heat transfer coefficients( $U)$ measurements}

The measurements of heat transfer coefficients were executed by the $\mathrm{gO}$ wireless measurement system for the non renovated apartment case study, Table 2 summarizes the results. While for the renovated apartment case, the $\mathrm{U}$ value was collected form the design report. The system consists of outside and inside nodes which are connected via LoRaSC radio link $(868 / 915 \mathrm{MHz})$ to the gateway. Therefore, it is possible to use the system in situations where no $\mathrm{WiFi}$ or mobile connection is available. The gateway is connected to the internet via a global $2 \mathrm{G} / 3 \mathrm{G}$ module and transmits all measured data in real-time to the cloud. Accordingly, for each U-value measurement two sensor nodes were used. One node is placed inside the building, illustrated in Figure 7 and measures the room temperature (Tin) and the heat flux through the wall (q). The other node (B) is placed outside or on the other side of the wall and measures the outside temperature (Tout). The surface temperature is also measured for both sensor nodes. The U-value is then calculated as the arithmetic mean of all measured data points during the entire measuring time by $(\mathrm{gO})$ online system. 


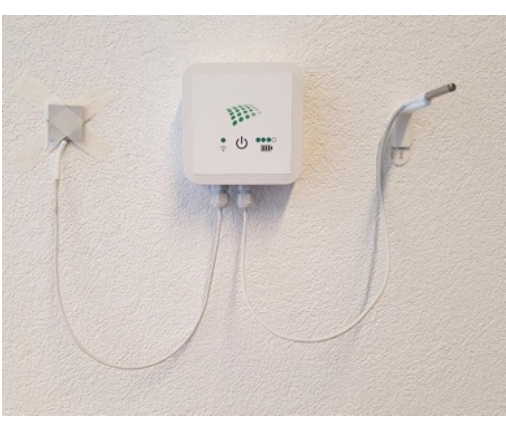

Figure 7: Heat transfer coefficient measurements, indoor node

Table 2: Walls heat Transfer coefficients, $U$

\begin{tabular}{|c|c|c|c|}
\hline Apartment & Wall type & $\begin{array}{c}\text { U Coeff. } \\
\text { W/m2K }\end{array}$ & Data \\
\hline \multirow{2}{*}{$\begin{array}{c}\text { Non } \\
\text { Renovated }\end{array}$} & External wall & 1.4 & \multirow{2}{*}{ Measured } \\
\cline { 2 - 3 } & adjacent wall & 2.7 & \\
\hline \multirow{2}{*}{ Renovated } & External Wall & 0.1 & \multirow{2}{*}{$\begin{array}{c}\text { Design } \\
\text { report }\end{array}$} \\
\cline { 2 - 3 } & adjacent Wall & 0.5 & \\
\hline
\end{tabular}

\section{Prediction of the indoor temperature}

The indoor air temperature is one of the dynamic parameters, which affects the building heating energy performance. Linear regression relations between the outdoor and indoor temperature were developed from short-term measurements to predict the indoor temperature values for each thermal zone in the apartments (bedroom, family room, living room, kitchen, bathroom) and accordingly to determine the required heating consumption for the heating season. For the sake of brevity, linear regression relations were clarified for only two thermal zones (bedroom and Family room), see Figure $8 \mathrm{a}$ and $8 \mathrm{~b}$.

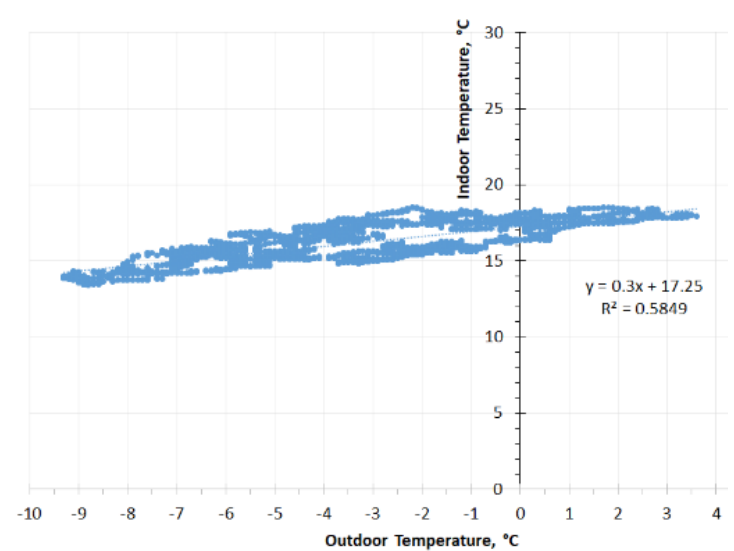

(a)

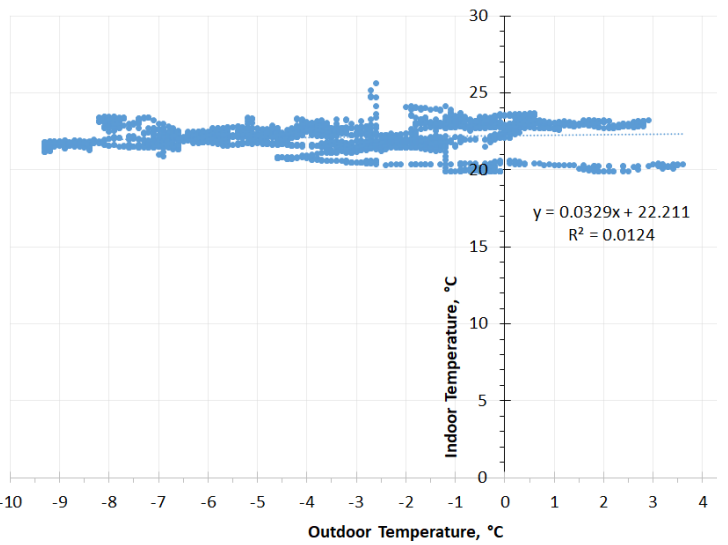

(b)

Figure 8: Regression relations-Non renovated aptartment (outdoor-indoor temperature), (a) Bedroom, (b) Family room

For the non-renovated apartment; the bed room linear regression denoted in equation (1) the coefficient of determination $\mathrm{R}^{2}$ equals to 0.6 indicates that this zone was mixed-load dominated zone (Heidarinejad et al., 2017). i.e. mixed load dominated zone indicates thermal loads dependency on both internal loads (Light, appliances, people) and external load dominated due to (weather conditions, infiltration).

This was due to the Scandinavian habit of sleeping with an open window. While, at the family room, the indoor /outdoor linear regression equation (2), $\mathrm{R}^{2}$ equals to 0.01 which indicated that this thermal zone was an internal load dominated zone.

$$
\begin{aligned}
\text { BR Temp } & =0.3 \times(\text { Ext.Temp. })+17.5 \\
\text { LivR Temp } & =0.03 \times(\text { Ext.Temp. })+22.5
\end{aligned}
$$

\section{Dynamic building model description}

The two apartments were modelled using TRNSYS software (Klein et al., 2004), which simulates dynamically the thermal behavior of buildings; it relies on modular approach to solve heat transfer equations described by FORTRAN subroutines. The input data included measured climatic data (external temperature, $\mathrm{RH}$ and solar radiation). In addition to the apartment's, internal gains such as the average daily electrical consumption which was applied to the numerical model through a schedule based on both the Smappee's collected data and interviews with the occupants. Whilst the predicted indoor temperature was calculated as a function of outdoor temperature by the regression analysis. See Table 3 and Table4. 
Table 3: Simulation model input data

\begin{tabular}{|c|c|c|}
\hline \multicolumn{3}{|c|}{ Indoor parameters } \\
\hline Air temperature & ${ }^{\circ} \mathrm{C}$ & $\begin{array}{c}\text { Predicted by the } \\
\text { regression models }\end{array}$ \\
\hline $\begin{array}{c}\text { Infiltration/ventilation } \\
\text { flow rate }\end{array}$ & $1 / \mathrm{s}$ & Measured \\
\hline $\begin{array}{c}\text { Electrical energy } \\
\text { consumption }\end{array}$ & $\mathrm{W} \mathrm{h}$ & Measured \\
\hline \multicolumn{3}{|c|}{ Climatic conditions } \\
\hline Air temperature & ${ }^{\circ} \mathrm{C}$ & \\
\hline Solar radiation & $\mathrm{W} / \mathrm{m}^{2}$ & Measured \\
\hline RH & $\%$ & \\
\hline
\end{tabular}

Table 4: Kitchen appliances use

\begin{tabular}{|c|c|}
\hline 7:00 am -8:00am & $50 \%$-On \\
\hline 13:00pm-14:00pm & $50 \%$-On \\
\hline $18: 00 \mathrm{pm}-19: 30 \mathrm{pm}$ & $100 \%$-On \\
\hline
\end{tabular}

\section{Regression sensitivity analysis}

In order to assess the potential impact of data resolution and numerical simulation time step, four case studies with 5 min, hourly time step, two weeks and one week regression models were considered. For each of these cases, the apartment heating energy consumption was estimated and compared to the measured data. Table5 summarized the four case studies.

Table 5: Case studies

\begin{tabular}{|c|c|c|}
\hline $\begin{array}{c}\text { Case } \\
\text { number }\end{array}$ & $\begin{array}{c}\text { Numerical } \\
\text { Simulation } \\
\text { Time step }\end{array}$ & $\begin{array}{c}\text { Linear } \\
\text { Regression(indoor/outdoor) } \\
\text { Temperature, }{ }^{\circ} \mathbf{C}\end{array}$ \\
\hline Case-1 & $5 \mathrm{~min}$ & 2 weeks and 5 min readings \\
\hline Case-2 & $5 \mathrm{~min}$ & 1 week and 5 min readings \\
\hline Case-3 & $5 \mathrm{~min}$ & 2 weeks and hourly readings \\
\hline Case- 4 & Hourly & 2 weeks and hourly readings \\
\hline
\end{tabular}

\section{Results}

The results section was divided into two parts; the first discussed the analysis of the heat losses and gains for the renovated and non-renovated apartments. The second part discussed the results of the regression sensitivity analysis.

\section{Building Energy losses and gains distribution}

The energy balance analysis for the both apartment has carried out to highlight the importance of measuring some parameters before and after renovation such as heat transfer coefficients and infiltration rate. For the nonrenovated apartment as clarified in Figure 9a the infiltration loss was $8.5 \mathrm{kWhm}^{-2}$ corresponding to $17 \%$ of the overall losses of $50 \mathrm{kWhm}^{-2}$. The energy losses through the apartment envelope was $83 \%$. Figure 10a clarifies the energy gains distribution with supply heating energy of $28.5 \mathrm{kWhm}^{-2}$ (57\% from the overall heat gains of $50 \mathrm{kWhm}^{-2}$ ). The solar and internal gains (people, appliances, light, etc.) represents the rest of the internal gains with a share of 7 and $14.5 \mathrm{kWhm}^{-2}$ respectively.

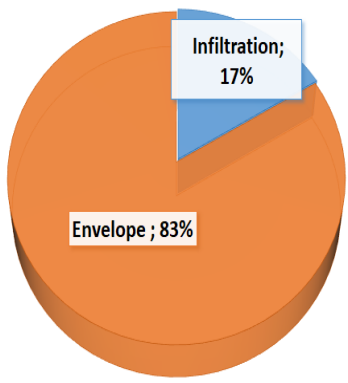

(a)

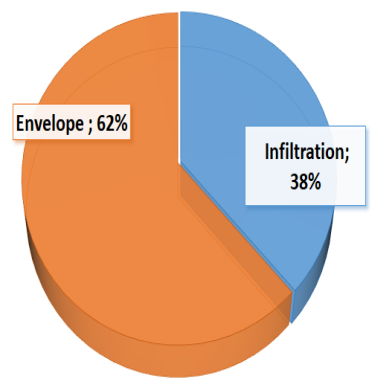

(b)
Figure 9: Numerical model results, distribution of the (a) Non renovated and (b) Renovated apartment's heat losses. The total heat loss was $50 \mathrm{kWh} / \mathrm{m}^{2}$ and 30 $\mathrm{kWh} / \mathrm{m}^{2}$ in $a$ and $b$, respectively.

On the other hand, it was expected that for the renovated apartment; the envelope energy losses would be improved due to the use of the insulation layers. As clarified in Figure $9 \mathrm{~b}$ the envelope losses reached $62 \%$ from the overall energy losses of $30 \mathrm{kWhm}^{-2}$. While the infiltration losses has increased to 38\%' which indicated the failure of the renovation process to improve the building air tightness. The supplied heating energy has improved to reach $10.5 \mathrm{kWhm}^{-2}$ out of $30 \mathrm{kWhm}^{-2}$ Figure $10 \mathrm{~b}$. It is important to highlight that the solar and internal gains after renovation have reached 5 and $14 \mathrm{kWh} / \mathrm{m}^{2}$ respectively and these shares are close to the nonrenovated apartment values, however the clarified percentages are due to the reduction of the overall heating requirements after renovation.

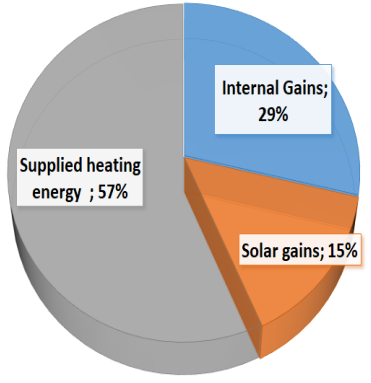

(a)

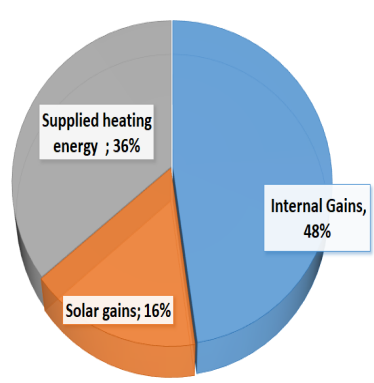

(b)
Figure 10: Numerical Model, Apartment's heat gains, (a) Non renovated, (b)Renovated.

\section{Regression sensitivity analysis}

- Weekly energy profiles comparison (Case-1)

As shown in Figure 11a for the non-renovated apartment, the calculated and actual energy profiles had a good agreement, which strengthen the fact that non-renovated apartments are mixed-load dominated zones and the indoor temperature could be correlated to the outdoor temperature. While for the renovated apartment Figure $11 \mathrm{~b}$ there was an average continuous deviation of $6 \mathrm{Wm}^{-2}$ between the actual and calculated energy profiles. The weekly heating profiles for the renovated and nonrenovated apartments was illustrated for only Case-1 for the sake of brevity. 


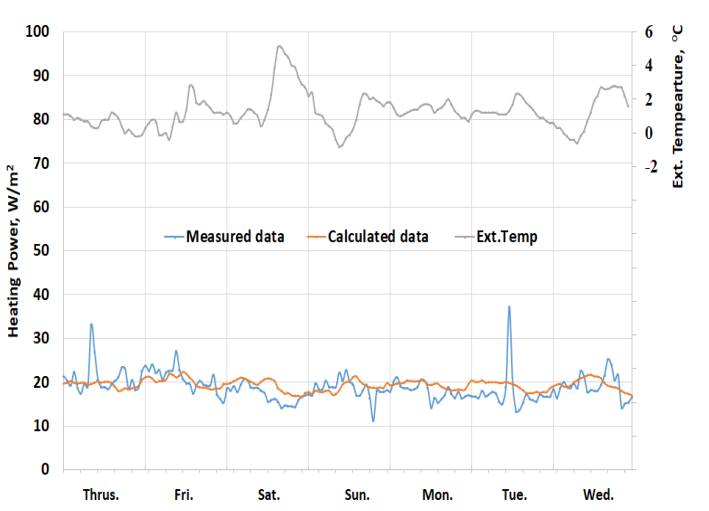

(a)

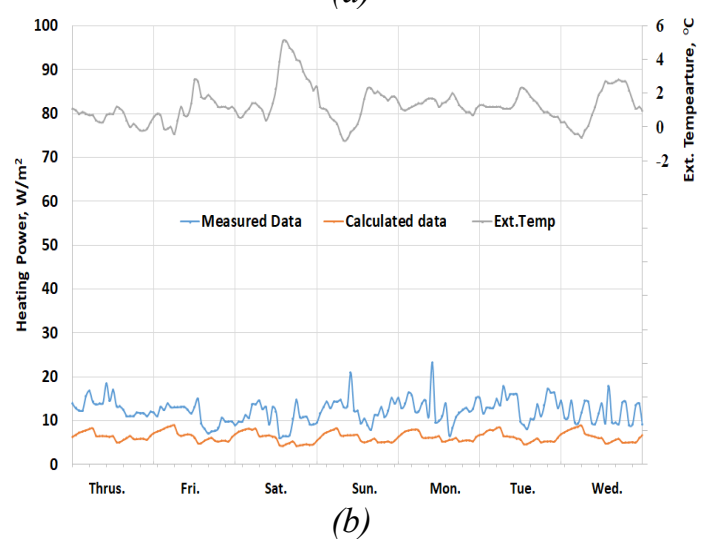

Figure 11: Apartment weekly heating energy profilesCase-1 (a) Non Renovated (b) Renovated

- Overall percentage difference (all case studies)

For the non-renovated apartment Figure 12, the sensitivity analysis revealed differences between simulated and real energy consumption in the ranged of $3 \%$ to $15 \%$. Case 1 , 2 and 3 recorded close results to actual consumptions with $3 \% \pm 1.5$. It is important to highlight that these cases have a common factor of using 5 minutes as a simulation time step. While Case 4 with the hourly simulation time step, the difference percentage was $15 \%$.

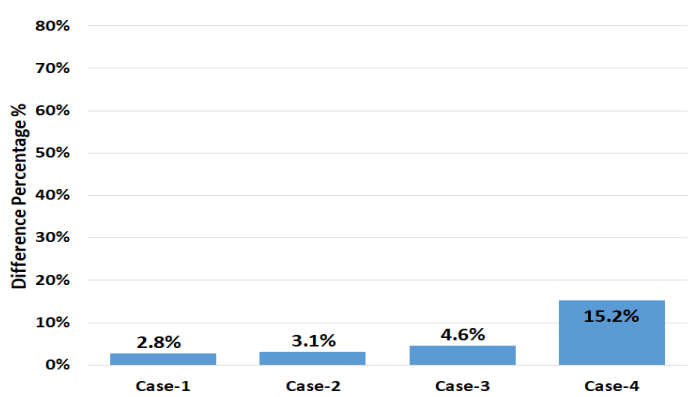

Figure 12: Actual Vs. simulated heating consumption, non-renovated apartment

In Figure 13, it was not effective to implement the linear regression relations to predict the indoor temperature as a function of the outdoor temperature at the renovated apartment study case. The difference between expected and actual energy consumption ranged from $41 \%$ for Case 1 to $44 \%$ for Case 4 .

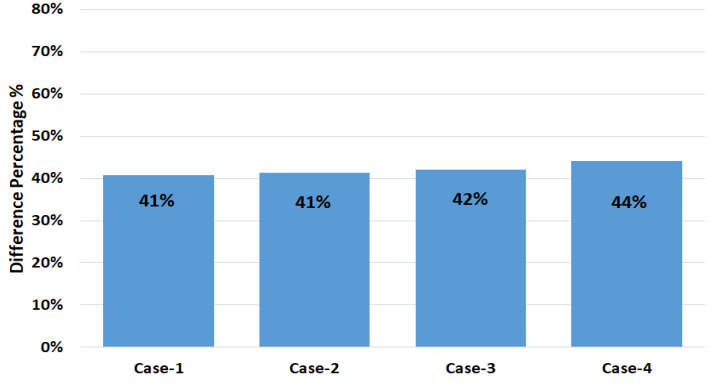

Figure 13: Actual Vs. simulated heating consumption, renovated apartment

\section{Limitations}

The study was based on measurements in two apartments and is neither representative for the Danish population nor the Danish building stock. In the two apartments, the relation between indoor and outdoor temperature could be approximated as linear and the use of linear regression was justified. However, in other apartments this may not be the case. In these cases, the proposed methodology would not predict the indoor temperatures well and the simulation accuracy would not be improved.

\section{Conclusions}

Pre-renovation measurements could improve the accuracy of prediction of conventional energy buildings tools. However, this strategy requires time and efforts especially for designers. Accordingly, this study investigated, i) the gains and losses share in the overall building energy balance, ii) the optimum time step for simulation and measurements and regression models time span. From this, the following was concluded:

a) Addressing each thermal zone inside the apartment by a linear regression model improved the numerical simulation accuracy, because the occupant behavior regarding the indoor temperature was considered.

b) The accuracy of the estimates compared to the measured performance increased with decreasing dynamic simulation time step.

c) The linear regression models could be implemented to benchmark building energy performance before renovation; however, after renovation it was not effective. This is due to that after renovation, the occupant behavior share in the overall energy consumption is higher. Accordingly, depending on energy measurements of three weeks might not describe the big picture.

d) The simplified linear regression model was accurate as long as the external temperature ranges between $-10^{\circ} \mathrm{C}$ to $8^{\circ} \mathrm{C}$. The regression method has been applied after the $15^{\text {th }}$ April which denotes the end of heating season and high discrepancy was noticed between the simulated and actual energy consumption.

\section{Acknowledgement}

This study was carried out under the framework of the REBUS project, Renovating Buildings Sustainably, www.rebus.nu, funded by the Innovation Fund Denmark, Realdania, Grundejernes Investerings fond, and companies involved in the project. 


\section{References}

Bruman, E., Mumovic, D., Kimpian, J. (2014). Towards measurement and verification of energy performance under the framework of the European directive for energy performance of buildings. Jouranal of Energy, 77, 153-163.

Bordass, B.; Cohen, R.; Field, J. (2004). Energy performance of non-domestic buildings: Closing the credibility gap. In Proceedings of the $3 \mathrm{rd}$ International Conference on Improving Energy Efficiency in Commercial Buildings, Frankfurt (Germany),Available online:

http://www.usablebuildings.co.uk/Accessed 07/ 2019

Bruno, R., Pizzuti, G., Arcuri, N., (2016). The Prediction of Thermal Loads in Building by Means of the EN ISO 13790 Dynamic Model: A Comparison with TRNSYS. Energy Procedia 101, 92-199.

DeWilde, P. (2014). The gap between predicted and measured energy performance of buildings: A framework for investigation. Automation in Construction 41, 40-49.

Directive 2010/31/EU of the European Parlimant https://eur-lex.europa.eu/ Accessed 02/2019.

GreenTEG AG: https://www.greenteg.com/ Accessed $02 / 2019$.

Elarga, H., Alifragki, D., Rode, C. (2018). Implementation of integrated wireless sensors technology in renovation of social housing buildings. A Danish case study. Proceedings from IBPC2018: International Building Physics Conference, Syracuse(USA) 935-940.

Heidarinejad, M., Mattise, N., Dahlhausen, M., Sharma, K., Benne, K., Macumber, D., Srebric, J. (2017). Demonstration of reduced-order urban scale building energy models. Energy and Buildings 156, 17-28

IC-Meter. http://www.ic-meter.com/ Accessed 02/2019.

Khoury, J., Alameddine, Z., Hollmuller, P. (2017). Understanding and bridging the energy performance gap in building retrofit. Energy Procedia 122, 217 222.

Klein, A. (2004). TRNSYS 16-A TRaNsient system simulation program, user manual. Solar Energy Laboratory. Madison: University of WisconsinMadison.
Smappee: https://www.smappee.com/ Accessed 06/2018.

Mendes, T., Godina, R., Rodrigues, E., Matias. J., Catalão, J.(2015). Smart home communication technologies and applications: Wireless protocol assessment for home area network resources. Energies 8, 7279-7311.

Maile, T., Bazjanac, V., Fischer, M., (2012). A method to compare simulated and measured data to assess building energy performance. Building and environment 56, 241-251.

Rosenberg, M., Zhang, J., Hart, R., Athalye, R. (2015). Roadmap for the Future of Commercial Energy Codes. The U.S. Department of Energy under Contract DE-AC05-76RL01830.

Petersen, S., \& Hviid, C. (2012). The European Energy Performance of Buildings Directive: Comparison of calculated and actual energy use in a Danish office. building. Conference of Building Simulation and Optimization, Loughborough (UK).

Petersen, J., Kristensen, J., Elarga, H., Andersen, R., Midtstraum A. (2018). Accuracy and air temperature dependency of commercial low-cost NDIR CO2 sensors: An experimental investigation. Proceedings of $4^{\text {th }}$ International Conference on Building Energy and Environment, Melbourne(Australia).

Pisello, A.L., Goretti,M., Cotana, F. (2012). A method for assessing buildings' energy efficiency by dynamic simulation and experimental activity. Applied Energy 97, 419-429.

Wireless tags: http://wirelesstag.net/ Accessed 02/2019.

Yuna, G., Steemers, K., (2011). Behavioural, physical and socio-economic factors in household cooling energy consumption. Applied Energy 88, 2191-2200. 